\title{
Direito à qualidade da educação e educação em direitos humanos: inter-relações e desafios
}

\author{
Right to educational quality and human rights education: \\ interrelations and challenges
}

\section{Derecho a una educación de calidad y educación en derechos humanos: interrelaciones $y$ desafios}

\author{
YRAMA SIQUEIRA FERNANDES* \\ VERA MARIA FERRÃO CANDAU**
}

\begin{abstract}
$\diamond$
RESUMO

Os direitos humanos são fruto de uma luta histórica. Sendo assim, são uma conquista social. O direito à educação também deve ser colocado em um patamar de conquista social. E o direito à educação de qualidade tem se apresentado como um real desafio no campo da educação atualmente. Neste artigo, procura-se analisar as relações possíveis entre o direito à educação de qualidade e o tema da educação em direitos humanos, tanto na produção científica quanto na pesquisa empírica realizada através de entrevistas com professoras do ensino fundamental. A pergunta principal do artigo é se há relações entre características de educação em direitos humanos e qualidade educacional nos dados coletados.
\end{abstract}

Palavras-chave: Direitos humanos. Direito humano à educação. Direito à educação de qualidade. Ensino fundamental.

\section{Abstract}

The human rights were conquered through a historical fight. The right to education must be considered as a social conquer. The right to educational quality has been established as a real challenge in the educational field nowadays. In this work, we aimed at analyzing the possible relations between the right to educational quality and the human rights education that can be found in the theoretical data and in the empirical data collected in interviews with elementary school teachers. The main question in this paper is if there are relations between human rights education characteristics and educational quality in the collected data.

Keywords: Human rights. Human right to education. Right to educational quality. Elementary school.

\section{RESUMEN}

Los derechos humanos son fruto de una lucha historica y, por lo tanto, son una conquista social. El derecho a la educación también es una conquista social. El derecho a la educación de calidad se debe plantear como un desafío a la educación en la acrualidad. En este trabajo profundizaremos en las relaciones posibles entre el derecho a la educación de calidad y la educación en derechos humanos, en la producción científica, así como en la investigación empirica realizada a traves de entrevistas con profesores de enseñanza básica. La cuestión principal en este artículo es si existen relaciones entre las características de educación en derechos humanos y la calidad de la educación en los datos recogidos.

Palabras clave: Derechos humanos. Derecho humano a la educación. Derecho a la educación de calidad. Enseñanza básica.

\footnotetext{
* Doutoranda em Educação pela Pontifícia Universidade Católica do Rio de Janeiro. Mestra em Educação pela Pontifícia Universidade Católica do Rio de Janeiro.E-mail: <yrama002@gmail.com>.

** Possui Doutorado e Pós-doutorado em Educação pela UniversidadComplutense de Madrid. É professora emérita do Departamento de Educação da Pontifícia Universidade Católica do Rio de Janeiro.E-mail: <vmfc@puc-rio.br>.
} 


\section{INTRODUÇÃO}

As relações entre o direito a uma educação de qualidade e educar em direitos humanos constituem uma questão ainda pouco trabalhada na produção acadêmica do nosso país. Para situá-la, é importante pontuar que o direito humano à educação é um dos principais direitos sociais. Por outro lado, convém ter presente que o conceito de direitos humanos não é consensual, vai variar de acordo com a orientação tomada quanto aos fenômenos jurídicos. Bobbio (2004, p. 16) afirma que é uma ilusão atribuir um fundamento absoluto para os direitos humanos, já que são construídos historicamente e, portanto, relativos.

Neste artigo, parte-se da afirmação de que os direitos humanos são frutos de uma luta histórica, assim como asseveram os autores que defendem uma concepção crítico-materialista de caráter histórico-estrutural. Segundo Dornelles (2005, p. 123), "por essa concepção, o reconhecimento de direitos e garantias resulta de um processo histórico marcado por contingências políticas, econômicas e ideológicas, e que se expressa através de uma conquista da história social". Sob esse ponto de vista, os direitos humanos são frutos de lutas sociais por direitos individuais e coletivos. Sua posterior positivação e as lutas pela efetivação e garantia se perpetuam até os dias de hoje. É importante ter em mente que um dos objetivos primordiais para o surgimento de direitos é a regulação da vida em comum dentro das necessidades das sociedades em contextos históricos específicos.

$\mathrm{O}$ direito à educação também advém de processo histórico e por esse motivo faz-se necessário abordar quais temas lhe estão associados na atualidade. A luta por sua efetivação colocou primeiramente o foco na universalização da escolarização. Na medida em que esse objetivo foi sendo alcançado, mesmo sem ter sido até hoje plenamente logrado, a questão da qualidade foi adquirindo cada vez maior centralidade. $\mathrm{O}$ direito à educação de qualidade tem se apresentado na atualidade como um desafio para a sua real democratização (OLIVEIRA e ARAÚJO, 2005; CAMPOS e HADDAD, 2006). Da mesma forma, muito se tem discutido sobre que qualidade seria essa, sendo esse um tema de disputas dentro do campo educacional. Também, nas últimas décadas, a educação em direitos humanos vem adquirindo cada vez maior importância nas políticas públicas da área de educação.

No presente trabalho, questiona-se a inter-relação entre direito a uma educação de qualidade e educação em direitos humanos, tanto do ponto de vista teórico, como a partir de uma pesquisa de campo, realizada através de entrevistas com professoras do primeiro segmento do ensino fundamental.
O artigo é composto de quatro partes, além desta introdução. A segunda parte faz algumas aproximações entre os temas do direito humano à educação e do educar em direitos humanos. A terceira focaliza a educação em direitos humanos em conexão com a qualidade educacional. Em sua quarta parte, o artigo contempla o campo empírico da pesquisa. Para finalizar, apresenta algumas considerações finais.

\section{DIREITO HUMANO À EDUCAÇÃo E EDUCAR EM DIREITOS HUMANOS: UMA APROXIMAÇÃO}

Desde a Revolução Francesa (1789) que o direito à instrução era concebido como condição da cidadania. Reis $(2003,764)$, no artigo sobre "O pão do direito à educação", desvela o quanto para os iluministas e revolucionários, como Danton, a educação respondia à necessidade coletiva de cidadania, tanto quanto era o pão para a sobrevivência do povo francês no frio do século XVIII. Entretanto, complementa Reis, "o direito à educação é um direito prioritário, mas não é direito a uma educação qualquer: é direito a uma educação com qualidade de direito do homem".

$\mathrm{Na}$ Declaração Universal dos Direitos Humanos (1948), a educação como um direito humano universal aparece no mesmo patamar do direito à vida, à segurança, à paz, à saúde e ao bem-estar, assim como os direitos humanos são concebidos com princípio e conteúdo do direito à educação.
Art. 26.
1. Toda pessoa tem direito à educação. A educação deve ser gratuita, pelo menos a correspondente ao ensino elementar fundamental. O ensino elementar é obrigatório. O ensino técnico e profissional deve ser generalizado; o acesso aos estudos superiores deve estar aberto a todos em plena igualdade, em função do seu mérito.
2. A educação deve visar à plena expansão da personalidade humana e ao reforço dos direitos do Homem e das liberdades fundamentais e deve favorecer a compreensão, a tolerância e a amizade entre todas as nações e todos os grupos raciais ou religiosos, bem como o desenvolvimento das atividades das Nações Unidas para a manutenção da paz (Declaração Universal dos Direitos Humanos. ONU, 1948).

Nesta segunda seção, apresentam-se algumas considerações acerca das aproximações entre o direito humano à educação e o educar em direitos humanos. Primeiramente é importante analisar o que postulam os dois itens do art. 26 da DUDH (Declaração Universal dos Direitos Humanos) acima citados. Em seu item primeiro, a 
Declaração afirma que toda pessoa tem direito à educação, o que podia ser considerado, à época, um avanço. Não há aqui a palavra cidadão, que supõe um exercício, mas sim a palavra pessoa concebida como sujeito de dignidade e direitos, sem nenhuma restrição a um dado Estado, e, portanto, universalizando o referido direito.

A Declaração ainda elenca o que a educação deve visar no item 2 do mesmo artigo. Esse item postula preceitos que condizem com o que posteriormente se intitulou como "educação em Direitos Humanos", já que seu conteúdo menciona que a educação deve "visar à plena expansão da personalidade humana, ao reforço dos direitos do Homem, à tolerância e à amizade ente as nações". Sendo assim, não basta que todos e todas tenham acesso à educação. É necessário também que a educação fornecida propicie expandir a humanidade de cada pessoa e ainda reforce o reconhecimento dos direitos e do seu exercício, daí porque a educação atua na perspectiva para, sobre ou em direitos humanos. Sobre essa educação que preconiza o desenvolvimento da personalidade humana autônoma e crítica, afirmam Candau (2012, p. 721) e Andrade (2008, p. 55):

A educação escolar não pode ser reduzida a um produto que se negocia na lógica do mercado; nem ter como referência quase que exclusivamente a aquisição de determinados "conteúdos", por mais socialmente reconhecidos que sejam. Deve ter como horizonte a construção de uma cidadania participativa, a formação de sujeitos de direito, o desenvolvimento da vocação humana de todas as pessoas nela implicadas (CANDAU, 2012, p. 721).

$\mathrm{Na}$ verdade, só somos verdadeiramente humanos se passarmos por um processo educativo. Ninguém nasce pronto e acabado como ser humano. Ao contrário, tornamo-nos humanos por um processo que chamamos de educação e ao qual temos o direito humano básico de vivenciá-lo (ANDRADE, 2008, p. 55).

Como os autores apropriadamente argumentam, o processo educativo deve nos tornar mais humanos em dignidade, reconhecimento e direitos. Todos e todas têm esse direito básico de serem educados, mas, como Candau (2012) afirma, educar não se restringe a ensinar conteúdos, ou a só explorar competências cognitivas, mas deve sim ter como seus objetivos a formação de sujeitos de direitos e o desenvolvimento da vocação humana.

Outro aspecto importante a ser assinalado se relaciona a formar pessoas que exijam o cumprimento de seus direitos. As pessoas só se tornarão verdadeiramente cidadãs quando exercitarem seus direitos de forma ativa e participativa. Daí a concepção de cidadania ativa que não insere apenas o voto, mas a participação social, exigindo a efetivação de seus direitos civis, políticos e sociais. Sobre essas questões, o PNDH-3 Plano Nacional de Educação de Direito Humanos- $3^{1}$ traz em seu item 23:

23. A democracia, entendida como regime alicerçado na soberania popular, na justiça social e no respeito integral aos direitos humanos, é fundamental para o reconhecimento, a ampliação e a concretização dos direitos. Para o exercício da cidadania democrática, a educação, como direito de todos e dever do Estado e da família, requer a formação dos (as) cidadãos (ãs).

A educação para alcançar a perspectiva da cidadania social deve assim ter como um de seus objetivos a formação de cidadãos ativos, que possam participar das decisões e do governo da sociedade, exigindo, realizando e criando direitos.

Saviani (2013) também contribui de modo significativo sobre o sentido de educar para a cidadania numa perspectiva democrática, quando afirma:

Com efeito, a educação, para além de se constituir em determinado tipo de direito, o direito social, configurase como condição necessária, ainda que não suficiente, para o exercício de todos os direitos, sejam eles civis, políticos, sociais, econômicos ou de qualquer outra natureza (SAVIANI, 2013, p. 745) .

No item 2 do artigo 26, a Declaração Universal afirma que a educação deve estimular "a compreensão, a tolerância e a amizade entre todas as nações e todas as raças e religiões." Esse ponto traz à baila o tema da diversidade. $\mathrm{O}$ respeito às diferentes culturas, países e religiões também deve ser parte integrante da educação a que se tem direito de acordo com a DUDH. Quanto a esse ponto, considera-se ainda mais importante, além de estimular a necessidade de se respeitar os "diferentes", empoderar as pessoas e/ou grupos historicamente inferiorizados e marginalizados. Tomasevsky $(2006$, p. 75), então relatora da ONU para o direto à educação, afirma:

O modelo de educação foi construído com base nas características daqueles que primeiro foram autodeclarados portadores do direito à educação, favorecendo o homem sobre a mulher, o colonizador sobre o colonizado (TOMASEVSKY, 2006, p. 75).

Essa afirmação leva a pensar que modelo de educação deve-se construir para que de fato inclua, sem discriminações, a todas as pessoas. Sabe-se, como afirma Comparato (2004, p. 1), que:

\footnotetext{
1 PNDH-3 - Plano Nacional de Educação de Direitos Humanos-3. Disponível em: <http://www.sdh.gov.br/assuntos/direito-para-todos/ programas/pdfs/programa-nacional-de-direitos-humanos-pndh-3>
} 
Todos os seres humanos, apesar de inúmeras diferenças biológicas e culturais que os distinguem entre si, merecem igual respeito, como únicos entes no mundo capazes de amar, descobrir a verdade e criar beleza. É o reconhecimento universal de que, em razão dessa radical igualdade, ninguém - nenhum indivíduo, gênero, etnia, classe social, grupo religioso ou nação pode afirmar-se superior aos demais.

Sendo assim, os diferentes necessitam de pertencimento e reconhecimento como sujeitos de direitos e para conquistarem a cidadania política, social e civil devem sim se constituir como sujeitos coletivos: a única trilha para se tornarem empoderados. O processo de colonização no Brasil, fundado em 388 anos de escravidão, gestou relações de desigualdades sociais profundas, e com elas processos de exclusão social. Pessoas e grupos que foram subalternizados passaram a conviver com relações de hierarquização, como se houvesse cidadãos e servos. Nesse processo, pessoas passaram a viver de forma inferiorizada quando do acesso aos serviços sociais em razão de sua origem étnica, de gênero e condições sociais. Outras, em face da condição de portar um tipo de deficiência ou conviver com transtornos psíquicos, também passaram a conviver com processos de segregação e exclusão, tendo que, ao longo da história, lutar pela igualdade e pelo respeito à diferença, mas também para serem tratadas de maneira diferenciada em virtude da condição especial dentro do sistema educativo.

Ainda sobre a diversidade e sobre a diferença, Piovesan (2006) afirma:

A efetiva proteção dos direitos humanos demanda não apenas políticas universalistas, mas específicas, endereçadas a grupos socialmente vulneráveis, enquanto vítimas preferenciais da exclusão. Isto é, a implementação dos direitos humanos requer a universalidade e indivisibilidade desses direitos, acrescidos do valor da diversidade [...]. Ao lado do direito à igualdade, surge, também, como direito fundamental, o direito à diferença. Importa o respeito à diferença e à diversidade, o que lhes assegura um tratamento especial (PIOVESAN, 2006, p. 719).

Respeito e valorização das diferenças é algo que propiciará o exercício de um direito à educação em um sentido mais amplo para as pessoas. A educação deve ter o papel de formar pessoas que exijam o cumprimento desses direitos. Só se torna verdadeiramente cidadão quando se é ativo e participativo na sociedade, exigindo assim a efetivação de direitos civis, políticos e sociais.

Neste item, são analisadas as contribuições que se considera fundamentais para o entendimento das relações entre o direito humano à educação e suas conexões com a educação em direitos humanos.

\section{EDUCAR EM DIREITOS HUMANOS E QUALIDADE DA EDUCAÇÃO: ARTICULAÇÕES}

Inicia-se afirmando que, para se estabelecer uma relação entre qualidade e educação em direitos humanos, é apropriado trazer os princípios da educação em direitos humanos presentes nas Diretrizes Curriculares Nacionais da Educação em Direitos Humanos (2013)²:

Art. 3을 A Educação em Direitos Humanos, com a finalidade de promover a educação para a mudança e a transformação social, fundamenta-se nos seguintes princípios:

I - dignidade humana;

II - igualdade de direitos;

III - reconhecimento e valorização das diferenças e das diversidades;

IV - laicidade do Estado;

V - democracia na educação;

VI - transversalidade, vivência e globalidade;

VII - sustentabilidade socioambiental.

Como se pode constatar, entre esses princípios se encontram o da dignidade humana e o da valorização das diferenças e diversidades. Como já foi abordado no item anterior, esses são muito importantes para a formação de cidadãos ativos e participativos. Para analisar a conexão entre a qualidade da educação e as características da educação em direitos humanos, inicia-se com a afirmação de Candau (2012, p. 724), que estabelece uma relação entre direito à educação, educação em direitos humanos e qualidade da educação:

No que diz respeito à inter-relação entre direito à educação e educação em direitos humanos, num primeiro momento, as reflexões sobre estes campos se deram de modo independente. No entanto, foram se aproximando progressivamente e foi sendo assumida a perspectiva que considera a educação em direitos humanos como um componente do direito à educação e elemento fundamental da qualidade da educação que desejamos promover. Sendo assim, estas duas preocupações se entrelaçam na busca da construção de uma educação comprometida com a formação de sujeitos de direito e a afirmação da democracia, da justiça e do reconhecimento da diversidade na sociedade brasileira (CANDAU, 2012, p. 724).

Essa afirmação permite reconhecer as estreitas relações entre a educação para formação de sujeitos de direitos, formação para a cidadania, reflexão e atuação no mundo e a educação em direitos humanos. Características

\footnotetext{
2 Diretrizes Curriculares Nacionais da Educação Básica. Portal MEC. Disponível em: <http://portal.mec.gov.br/index.php?option=com docman\&task $=\mathrm{doc}>$. Acesso em: setembro de 2014.
} 
que foram igualmente conectadas com a qualidade da educação.

A partir dessas considerações, realizou-se uma pesquisa empírica orientada a identificar as concepções de professoras do primeiro segmento do ensino fundamental sobre o direito à educação e suas conexões com a educação em direitos humanos e com a qualidade da educação. A seguir, apresenta-se o campo empírico desta pesquisa, iniciando-se pelas informações gerais sobre as professoras entrevistadas e, em seguida, aborda-se a análise dos depoimentos das professoras.

\section{DIREITO À EDUCAÇÃO DE QUALIDADE E EDUCAR EM DIREITOS HUMANOS: O QUE PENSAM PROFESSORAS DO ENSINO FUNDAMENTAL}

A pesquisa empírica contemplou 12 entrevistas semiestruturadas com professoras do primeiro segmento do ensino fundamental. Dez entrevistas foram realizadas em ambiente escolar. Nesses casos, a direção permitiu o uso da sala de leitura e o horário livre das professoras na escola. Duas entrevistas foram realizadas em outros ambientes, uma aconteceu em um café e outra em uma universidade. Apesar de a maioria das entrevistas terem sido realizadas em ambiente escolar, as professoras não demonstraram constrangimento.

Os sujeitos que integram a pesquisa são docentes que estão em exercício no primeiro segmento do ensino fundamental de escolas públicas do município do Rio de Janeiro, selecionadas aleatoriamente. Contemplou-se na pesquisa professoras que tinham anos de experiência, de modo a poder captar relatos mais diversificados e, assim, perceber se haveria dados diferentes nos relatos das mais experientes e das menos experientes. Cinco professoras exercem o magistério há mais de 20 anos, duas têm entre 11 e 15 anos de docência e cinco entre três e 10 anos.

Um fato que chamou a atenção no trabalho de campo foi que algumas professoras, além do curso normal, têm mais de uma graduação. Três possuem três graduações ${ }^{3}$, seis têm duas graduações e três possuem uma graduação. Esse dado demonstra que, entre as professoras entrevistadas, há uma tendência à procura pelo aperfeiçoamento. Sobre o território em que atuam, nove docentes trabalham na zona norte do Rio de Janeiro, duas estão na zona sul do Rio de Janeiro e uma atua na Baixada Fluminense. Todas as professoras tiveram experiências no entorno de comunidades e cinco, em comunidades. Relatos sobre o território são importantes para delimitar a situação social das escolas mencionadas pelas professoras.

\footnotetext{
3 Aqui, considera-se o Normal, ou formação de professores, como uma graduação no nível médio.
}

A seguir, alguns depoimentos acerca do território:

“(...) eu entrei na rede pública com 20 anos de idade, eu fui trabalhar no Complexo do Alemão, na época em que não era pacificado ainda (...), eu me jogava no chão quando dava tiro, eu era responsável pela vida de trinta crianças. (...) eu nunca iria imaginar que eu iria passar aquilo (...) a faculdade não me preparou para isso (...)." (Formação de Professores - Letras Port. Esp. - Fonoaudiologia)

“(...) outro dia, uma criança ficou aqui até às cinco da tarde, desde o período da manhã, e a nossa direção (...) foi levá-la em casa. Vieram todos chorando porque ela mora em um buraco, (...) a gente pode melhorar o que for aqui, chegando lá, ela não vai ter acesso aos direitos que ela merece, (...)." (Formação de Professores - Serviço Social)

"Hoje, para mim (o maior desafio), são as questões sociais. (...). Por exemplo, a questão da droga (...) eu trabalho com os filhos da droga no Complexo de Alemão, então isso para mim é muito chocante (...)." (Normal-Pedagogia-História)

Pelos depoimentos, é possível perceber que as professoras têm desafios a enfrentar quanto ao território onde as escolas estão localizadas. Todas as questões citadas têm impacto direto na escola.

A qualidade da educação e as características de educação em direitos humanos foram mencionadas pelas entrevistadas. Porém, antes de começar a relatar acerca dos depoimentos sobre esses temas, é oportuno salientar que a palavra qualidade não era mencionada nas primeiras perguntas. O tema só apareceu a partir da pergunta 19 específica. Isso foi feito de maneira proposital para não influenciar as respostas. Nos pré-testes do roteiro da entrevista, os professores trouxeram o tema da qualidade educacional sem que eles fossem perguntados sobre ele. As menções sobre qualidade ocorreram em algumas respostas iniciais. Este depoimento de uma professora ilustra essa realidade. Quando indagada sobre "quando falo a expressão 'direito à educação', o que vem primeiro à sua cabeça?”, respondeu:

\footnotetext{
" $O$ direito à educação, eu acho que foi uma conquista, como eu já disse pela legislação, pela Constituição brasileira, pelo Estatuto da Criança e do Adolescente. A sua obrigatoriedade é uma conquista, mas o direito visto de outra forma, como lei, ele ainda não se faz cumprir, como deveria, porque falta uma, ou estratégias, ou competência política de um dirigente ou de uma nação. Eu sei que melhorou muito, mas um dirigente ou todo mundo que trabalha com educação, que faça isso, que cobre que isso aconteça, que todas essas leis possam estar dando suporte para isso acontecer, uma qualidade na educação." (Normal - Pedagogia)
} 
Como se pode constatar, a qualidade da educação foi abordada mesmo que essa questão não fosse perguntada diretamente. Em outros questionamentos gerais, como "o que você considera mais importante no seu trabalho?", algumas professoras trouxeram características do ato de educar como um processo de educação para a vida em sociedade, que implica a aquisição de valores humanos. Nesse sentido, os valores, como uma das dimensões éticas da educação em direitos humanos, encontram-se atrelados à concepção de qualidade educacional, como os itens anteriores deste artigo apresentaram. A seguir, alguns depoimentos:

“(...) eu acho que o mais importante na nossa tarefa é fazer com que o nosso aluno aprenda. Desde os conteúdos em si que você quer trabalhar, quanto às situações dos valores, o saber lidar com situações de vida, porque eu acho isso importante também, não somente os conteúdos em si, os conteúdos do núcleo comum, mas também valores." (Normal - Letras Port.)

"Eu acabo olhando a vida deles e tento suprir além da educação. Então, quando você fala da parte mais importante, para mim, aqui, é ser um espelho, é trazer esperança (...) trazer um pouco de vivência, trazer que a realidade pode ser mudada. (...). Eu acho que para ser professor você tem que querer. (...). Porque você é parte fundamental de alguém. Você está fazendo parte de um periodo de crescimento de entendimento do que é o mundo, você participa da parte lúdica de uma criança, então o professor é muito importante para o nosso ser pessoal, você é parte formadora de alguém."(Formação de Professores - Serviço Social)

Nessas declarações, as professoras trazem a educação formadora, para valores, para a participação no mundo. Apesar de considerar os aspectos éticos da educação, as docentes não narraram de forma explícita em seus depoimentos a relação com os direitos humanos e nem com a cidadania, ambas características do direito à educação na Declaração Universal dos Direitos Humanos, abordado anteriormente neste trabalho.

Ao responderem à pergunta "ao se falar sobre direito à educação, o que vem em primeiro lugar na sua cabeça?", duas professoras disseram se tratar de uma educação que resulte no acesso aos direitos, uma educação ampliada e que respeita as diferenças presentes no contexto sociocultural. A seguir, os depoimentos:

"Mudança. Se este direito for executado, assegurado, praticado, a gente terá uma mudança muito grande. A gente tem uma quebra enorme da maior arma que se tem hoje do Estado que é a alienação, eu acho. Eu acho que se a gente tiver direito à (...) o direito à educação foi expandido, automaticamente este aluno torna-se um cidadão assim (...). Nós somos cidadãos devido ao acesso aos direitos (...)." (Formação de Professores - Serviço Social)

"Direito à educação... igualdade de oportunidades. Quando eu falo direito à educação para mim, vem igualdade de oportunidades, quando eu penso direito à educação, eu estou pensando que toda pessoa, todo sujeito tem direito a estar na escola, a ter uma educação de qualidade, a ter uma educação ampliada, e quando eu falo uma educação de qualidade, tem que ser uma educação igualitária, igualitária respeitando as diferenças, étnicas e culturais, mais igualitárias no sentido de formação." (Normal - Serviço Social)

Essas afirmações focalizam uma concepção de educação como formação da pessoa e do cidadão, abordando uma visão ampla. Ambas as professoras são graduadas em Serviço Social. De certa maneira, arrisca-se a afirmar que a formação universitária pode ter contribuído nesse aspecto. Decidiu-se perguntar mais no intuito de aprofundamento do tema. A seguir, o depoimento de uma das professoras:

\begin{abstract}
“(...) engraçado, eu não vejo educação só na escola, eu não consigo ver. Para mim é mundo, é uma ideia global. Direito à educação para mim é uma extensão, a quebra desse paradigma de escola, uma educação global, uma educação para o mundo, uma educação além de libertadora, que possa ser de alcance geral, uma educação para saúde, para direitos (...) direito à educação é o direito à vida. (...) Direito à educação para mim é o direito à vida porque eu não vejo um fim." (Formação de Professores - Serviço Social)
\end{abstract}

Nessa narrativa são explicitadas algumas características de educação em direitos humanos, como a educação numa perspectiva libertadora, voltada para a vida em sociedade. Essa perspectiva é classificada aqui como qualidade. A professora faz menção a outros direitos, remetendo ao conceito de que os direitos humanos são indivisíveis e inter-relacionados (DORNELLES, 2006). E a compreensão da educação para a formação articula-se com a educação para formação de sujeitos de direitos, capazes de exercer a cidadania ativa, de exigir o cumprimento dos direitos e responsabilizar-se também pela sua efetivação. Características que são contempladas por Candau (2012).

Ao perguntar explicitamente sobre o que seria uma educação de qualidade, as professoras discorrem novamente sobre características de educação em direitos humanos, como se pode comprovar nestes depoimentos:

\footnotetext{
"Para mim, educação de qualidade é fazer com que $o$ aprendizado seja um aprendizado respeitando as diferenças, que promova igualdade, ensino de
} 
qualidade, que não se limite apenas à realidade inserida naquele contexto das crianças e da escola, mas que possa abrir espaços e oportunidades de outro horizonte, de outras vias, de outros caminhos (...)." (Normal - Serviço Social)

"São oportunidades que você abre para que o aluno se perceba e perceba as habilidades que ele tem. Isso para mim é educação de qualidade. (...) Educação de qualidade passa muito pela minha visão de mundo." (Normal - Letras)

“(...) que te dê acesso às mais diversas expressões da educação: arte; música (...). E que principalmente te dê essa visão de mundo, essa ideia, essa reflexão; é se debruçar sobre as coisas do mundo (...)." (Formação de Professores - Serviço Social)

Pode-se constatar nessas falas das educadoras que a preocupação com a qualidade educacional foi algo que esteve presente em primeiro lugar, já que as professoras mencionaram qualidade educacional mesmo sem serem perguntadas acerca do tema. No momento que se questionou o tema mais diretamente, as docentes abordaram o fato de que a educação precisa estar focalizando além de conteúdos. Foi nesse ponto que se chegou às características de educação em direitos humanos. Para uma educação de qualidade, as professoras trouxeram que é necessário que esta esteja proporcionando um respeito às diferenças étnico-raciais e culturais, que esteja presente nela a formação para o exercício de direitos e, por fim, que seja emancipatória, pois assim estará formando cidadãos para uma atuação no mundo.

\section{CONSIDERAÇõES FINAIS}

O objetivo central deste artigo foi primeiramente abordar o tema do direito à educação de qualidade e suas inter-relações com a educação em direitos humanos, a partir de contribuições teóricas e oriundas de uma pesquisa de campo.

Em primeiro lugar, o artigo constatou que o tema da qualidade educacional é ainda o grande desafio no tocante à real democratização da educação (OLIVEIRA e ARAÚJO, 2005; CAMPOS e HADDAD, 2006). Como passo seguinte, o trabalho aborda as aproximações teóricas entre o direito à educação de qualidade e a educação em direitos humanos. Nesse ponto, autores como Candau (2012), Andrade (2008), Tomasevsky (2006) e Piovesan (2006) foram citados, pois explicitam algumas características de educação em direitos humanos que devem ser contempladas, tais como a valorização das diferenças, a formação humanizadora, a formação para valores e para uma cidadania participativa.
Após a análise dessas contribuições, foi apresentado o campo da pesquisa empírica realizada, focalizando as entrevistas realizadas com professoras do primeiro segmento de ensino fundamental. Pôde-se constatar que a empiria esteve afinada com os achados teóricos. As professoras se mostraram preocupadas com a qualidade educacional e a pontuaram como um desafio real na atualidade. Referiram-se também às características da educação em direitos humanos, relacionando-as com a qualidade educacional.

Como uma última contribuição, recomenda-se a realização de mais pesquisas e estudos que abarquem o tema da educação em direitos humanos em suas inter-relações com as questões atreladas à qualidade educacional. São ainda raros os estudos acerca dessa temática. É necessário começar a pensar a qualidade educacional de forma mais ampla, mais abrangente, não reduzida à aquisição de conteúdos específicos, medidos através das avaliações de larga escala. As pesquisas são um modo de se contribuir para o conhecimento. E, através delas, podese tentar promover uma educação que seja emancipatória e que contribua de fato para a formação dos educandos como cidadãos comprometidos com a transformação da sociedade, uma perspectiva de humanização articulada com o compromisso social com a humanidade.

\section{REFERÊNCIAS}

ANDRADE, Marcelo. Educação como direito humano e a formação de educadores/as em direitos humanos. In: CANDAU, Vera Maria; SACAVINO, Suzana. Educação em direitos humanos: temas, questões e propostas. Petrópolis: Editora DP, 2008.

BOBBIO, Norberto. A era dos direitos. 13. ed. Rio de Janeiro: Elsevier, 2004.

BRASIL. Diretrizes curriculares nacionais da educação básica. Portal MEC. Disponível em: <http://portal.mec.gov.br/ index.php?option $=$ com_docman $\&$ task $=\mathrm{doc}>$. Acesso em: set. 2014

Programa Nacional de Direitos Humanos (PNDH-3) Secretaria Especial dos Direitos Humanos da Presidência da República. Rev. e atual. Brasília: SEDH/PR, 2010. Disponível em: <http://www.sdh.gov.br/assuntos/direito-para-todos/ programas/pdfs/programa-nacional-de-direitos-humanospndh-3>. Acesso em: set. 2014.

CAMPOS, Maria Malta; HADDAD, Sérgio. O direito humano à educação escolar pública de qualidade. In: HADDAD, Sérgio; GRACIANO, Mariângela (Org.). A educação entre os direitos humanos. São Paulo: Autores Associados, Ação Educativa, 2006. p. 85 .

CANDAU, Vera Maria Ferrão. Direito à educação, diversidade e educação em direitos humanos. Educação e Sociedade, Campinas, v. 33, n. 120, p. 715-726, 2012.

COMPARATO, Fábio Konder. A afirmação histórica dos direitos humanos. São Paulo: Saraiva, 2004. 
DORNELLES, João Ricardo W. O que são os direitos humanos? 2. ed. São Paulo: Brasiliense. 2006.

Sobre os direitos humanos, a cidadania e as práticas democráticas no contexto dos movimentos contra hegemônicos. Revista da Faculdade de Direito de Campos, ano VI, n. 6, p. 121-155, 2005.

FERNANDES, Yrama Siqueira; CANDAU, Vera Maria Ferrão (Orient.). Direito à educação? Pergunta complicada (...). $\mathrm{O}$ que pensam os professores do primeiro segmento do ensino fundamental. 154f. Dissertação (Mestrado em Educação) Pontifícia Universidade Católica do Rio de Janeiro, 2015.

NAÇÕES UNIDAS. Declaração Universal dos Direitos Humanos: adotada e proclamada pela Resolução 217 (III) da Assembleia Geral das Nações Unidas em 10 de dezembro de 1948. Brasília, DF, 1998. Disponível em: <http://unesdoc. unesco.org/images/0013/001394/139423por.pdf $>$. Acesso em: 20 out. 2014.

OLIVEIRA, Romualdo Portela de; ARAÚJO, Gilda Cardoso de. Qualidade do ensino: uma nova dimensão da luta pelo direito à educação. In: Revista Brasileira de Educação, Rio de Janeiro, n. 28, jan.-abr. 2005. Disponível em: <http://www. scielo.br/pdf/rbedu/n28/a02n28.pdf>. Acesso em: 10 out. 2014.

PIOVESAN, Flávia. Concepção contemporânea de direitos humanos. In: HADDAD, Sérgio; GRACIANO, Mariângela (Org). A educação entre os direitos humanos. São Paulo: Autores Associados, 2006.

REIS, Monteiro. O pão do direito à educação. In: Educação e Sociedade, Campinas, v. 24, n. 84, p. 763-789, set. 2003. Disponível em: <http://www.scielo.br/pdf/es/v24n84/a03 v2484.pdf>. Acesso em: 10 jan. 2017.

SAVIANI, Dermeval. Vicissitudes e perspectivas do direito à educação no Brasil: abordagem histórica e situação atual. Educação e Sociedade, Campinas, v. 34, n. 124, p. 743-760, 2013.

TOMASEVSKY, Katarina. Por que a educação não é gratuita? In: HADDAD, Sérgio; GRACIANO, Mariângela (Org.). A educação entre os direitos humanos. São Paulo: Autores Associados, 2006.

\section{ANEXO 1 \\ Roteiro das entrevistas semiestruturadas}

\begin{tabular}{|c|c|}
\hline Primeiras informações & $\begin{array}{l}\text { - Fale um pouco sobre sua trajetória profissional. } \\
\text { - Com sua experiência, o que você considera mais significativo na educação hoje? } \\
\text { - O que você considera mais importante no seu trabalho? } \\
\text { - Em seu dia a dia, qual é o seu maior desafio? }\end{array}$ \\
\hline $\begin{array}{l}\text { Direito à educação como } \\
\text { direito humano }\end{array}$ & $\begin{array}{l}\text { - Em sua opinião, quais avanços o Brasil conquistou com relação à educação para todos? } \\
\text { - Quais são ainda os desafios? } \\
\text { - Você diria que todas as crianças, com qualquer especificidade, estão presentes na escola? } \\
\text { - Em sua opinião, há dificuldades ou desafios quanto à questão da inclusão de crianças com diferentes } \\
\text { características (sociais, culturais, étnico-raciais, de gênero, religiosas, físicas, mentais, etc.) na escola? } \\
\text { Se sim, quais seriam esses desafios? }\end{array}$ \\
\hline Direito à educação & $\begin{array}{l}\text { - Ao se falar sobre direito à educação, o que vem em primeiro lugar na sua cabeça? } \\
\text { - educação? Se sim, conte sua experiência. } \\
\text { - Em sua opinião, quem são os responsáveis por promover o direito à educação? } \\
\text { - Qual é o papel da escola nessa promoção? } \\
\text { - Qual é o papel do Estado? } \\
\text { - Qual é o papel do professor? } \\
\text { - Qual é o papel da família e das crianças? } \\
\text { - Como se dão as relações entre esses atores na educação hoje? } \\
\text { - Há, em sua opinião, algum ator que tenha um papel mais importante na garantia desse direito? Se sim, } \\
\text { quem seria e por quê? } \\
\text { - Você poderia contar alguma prática que você tenha desempenhado em suas aulas a fim de garantir esse } \\
\text { direito? }\end{array}$ \\
\hline Qualidade & $\begin{array}{l}\text { - Hoje, discute-se muito a qualidade na educação. O que é para você uma educação de qualidade? } \\
\text { - Quais aspectos têm sido conquistados com relação à qualidade? } \\
\text { - Quais são os desafios para a promoção de uma educação pública de qualidade? } \\
\text { - Dentre esses desafios, qual você escolheria para dar atenção em primeiro lugar? Qual você considera o } \\
\text { mais importante? } \\
\text { - O que você pensa sobre as avaliações, sejam as da Prefeitura ou as nacionais? }\end{array}$ \\
\hline
\end{tabular}

